\title{
A PROSPECTIVE STUDY TO ASSESS THE FUNCTIONAL OUTCOME FOLLOWING ORIF VS PERCUTANEOUS FIXATION IN SCAPHOID FRACTURE
}

\section{Orthopaedics}

\begin{tabular}{ll} 
Ravi Mehrotra & Assistant Professor Department Of Orthopaedics, PCMS \& RC Bhopal, MP, India \\
\hline Sanjeev Mahawar & Assistant Professor Department Of Orthopaedics, PCMS \& RC Bhopal, MP, India \\
\hline Dhruv Lashkare & Senior Resident Department Of Orthopaedics, PCMS \& RC Bhopal, MP, India
\end{tabular}

Dhruv Lashkare

Raj Jaiswal*

PG $3^{\text {rd }}$ Year Department OfOrthopaedics, PCMS \& RC Bhopal, MP, India

*Corresponding Author

\section{ABSTRACT}

The study aimed to assess clinical, radiological as well as functional outcome in patients of scaphoid fracture following open reduction as compared to percutaneous fixation with Herbert Screw. This study was conducted at Department of orthopedics, for 1 year on 30 patients of scaphoid fracture. Fractures were first tried for percutaneous fixation using volar approach, ORIF with volar approach was used when adequate reduction was not achieved. Patients were followed at 2 week interval till union. Clinical assessment at final followup was performed using MMWS. The mean mean duration of presentation after injury of 19.9 days (3 to 162 days). The mean MMWS score was 93.8 (90-100) for percutaneous and $83.8(70-95)$ for ORIF. Since fracture treated with percutaneous fixation are associated with early union and early return to functional activity as compared to ORIF, Herbert screw for fixation with percutaneous technique for scaphoid fracture must be encouraged for displaced or undisplaced fracture.

\section{KEYWORDS}

Percutaneous Fixation, Orif, Mmws, Scaphoid Fracture, Bhopal

\section{INTRODUCTION:}

The word scaphoid has been derived from a Greek word "skaphos" which mean boat due to its shape. ${ }^{[1]}$ The scaphoid bone fracture account to about 80 to $90 \%$ fracture of all carpal bones. Scaphoid fracture are commonly encountered in young, adult males. ${ }^{[2]}$ The management of displaced, comminuted, and unstable fractures is only surgical intervention, however, management of undisplaced or minimally displaced surgical fracture is controversial. Literature suggests that patients with undisplaced fracture of scaphoid must be initially managed with the help of cast immobilization for 2 to 3 months. ${ }^{[3,4,3}$ Casting is an ancient technique that has traditionally been reserved for distal pole fractures and nondisplaced waist fractures, with union reported to occur at a mean of 53 days and 65 days respectively. ${ }^{[6]}$ Cast has been associated with longer time of union which inturn has multiple drawbacks which include sclerosis, comminution, translation and location in the proximal pole. ${ }^{[6]}$ Apart from non union, other complications of displaced fracture of scaphoid include increased rate of redisplacement and delayed union, when managed with cast immobilization alone. ${ }^{[7}$

Alternative management of scaphoid fracture include early operative intervention with screw fixation which not only limits the need for a cast, but may also allow earlier return to sports and work. ${ }^{[5,9,10]}$ The rate of complications such as non union are much lower for non displaced fractures and complication rate are almost nil when a non displaced fracture is adequately treated and protected.$^{[11]}$ However non union rate for displaced fractures is approximately $50 \%$ as compared to $10 \%$ non union rate of undisplaced fracture. ${ }^{[3,12,13\}}$ The occurrence of non union is responsible for various sequlae i.e. altered carpal biomechanics, pain, diminished range of motion of wrist, poor grip strength etc. ${ }^{[14]}$ Since rates of nonunion scaphoid fractures treated with conservative management are quite high, thus, open reduction with internal fixation (ORIF) has been recommended.

Open reduction and internal fixation technique for management of fracture of scaphoid was first introduced by McLaughlin ${ }^{[17]}$ and then the results were reproduced positively by various other studies. ${ }^{[18}$ Percutaneous fixation is also an alternative and simple technique for management of scaphoid fracture ${ }^{[19,20]}$ Both the methods have shown superiority over management of displaced fracture when compared to cast immobilization. The present study aimed to assess clinical, radiological as well as functional outcome in patients of scaphoid fracture following open reduction as compared to percutaneous fixation with Herbert Screw.

\section{METHODS:}

The present study was conducted as an interventional study at a tertiary care Centre, Bhopal for a period of 2 years i.e. from $1^{\text {st }}$ November 2017 to $20^{\text {th }}$ October 2019. A total of 34 cases of scaphoid fracture reported to the study area during the study period. Inclusion criteria was patients of acute scaphoid fracture, patients with delayed union or fractures showing no sign of healing after 12 weeks of cast immobilization. Patients with distal radial tuberosity fracture, or presenting with osteonecrosis, patients with previous wrist injury or any other associated fracture around the wrist were excluded.

Written consent was obtained from all the study participants. The present study was conducted on 30 patients out of 34 cases of scaphoid fracture fulfilling the inclusion criteria. All the cases were treated using Herbert screw. Patients were subjected to $\mathrm{X}$ ray wrist postero-anterior view, lateral view, semipronation oblique and antero-posterior view to assess the scaphoid fracture. Injuries were graded according to Herbert and Fisher Classification.

All fractures were first tried for percutaneous fixation using volar approach, patients in whom adequate reduction was not achieved with percutaneous method, ORIF with volar approach was used. However patients with history of fracture more than 5 months were managed with ORIF and bone grafting directly.

Post operatively, cast immobilization was done for all the patients. Patients were followed at 2 weeks, 6 weeks and 10 weeks and then every two weeks till fracture union post operatively. The minimum follow up was twelve months. After 2 weeks of operative management sutures were removed whereas cast was removed at 6 weeks and a removable wrist immobilizer brace was tied for next four weeks. Also all patients were advised physiotherapy with hand grip strengthening exercise and active assisted range of motion exercise.

At each follow up, clinical and radiological examination was conducted to assess the healing and union. Union was considered to have occurred when there was no tenderness at the anatomical snuff box or at scaphoid tubercle and there was evidence of trabeculae crossing fracture on at least two views. Clinical assessment at final follow up was performed using Modified Mayo Wrist Score (MMWS). To assess grip strength, patients were asked to squeeze the examiners index finger, and the strength was compared on contralateral side. Range of motion was measured using goniometer.

Data analysis- Data was compiled using Ms Excel and analysed using IBM SPSS software version 20. Numerical variables were expressed as mean and standard deviation. MMWS score was calculated for each patient for ORIF and percutaneous method separately.

\section{RESULTS:}

The present study included 30 patients with scaphoid fracture with mean age of $32.5 \pm 7.94$ years and mean duration of presentation after injury of 19.9 days ( 3 to 162 days). 
Table 1: Distribution of patients according to socio-demographic profiles and details of approach, MMWS and complication.

\begin{tabular}{|c|c|c|c|c|c|c|c|c|c|}
\hline S no & $\mathrm{AGE}$ & SEX & SIDE & Herbert Type & Time To Surgery (Days) & Approach & \begin{tabular}{|l|}
$\begin{array}{l}\text { Time To Union } \\
\text { (Week) }\end{array}$ \\
\end{tabular} & \begin{tabular}{|l} 
MMWS \\
(POINTS)
\end{tabular} & Remark \\
\hline 1 & 32 & $\mathrm{~F}$ & $\mathrm{~L}$ & B2 & 5 & Orif Volar & 12 & 85 & \\
\hline 2 & 34 & $\mathrm{~F}$ & $\mathrm{R}$ & B2 & 8 & Percutaneous Volar & 10 & 90 & \\
\hline 3 & 45 & $\mathrm{M}$ & $\mathrm{R}$ & B2 & 8 & Percutaneous Volar & 10 & 90 & \\
\hline 4 & 22 & $\mathrm{M}$ & $\mathrm{L}$ & B2 & 3 & Orif Volar & 10 & 95 & \\
\hline 5 & 51 & $\mathrm{M}$ & $\mathrm{R}$ & $\mathrm{C}$ & 162 & Orif Volar & 14 & 80 & $\begin{array}{l}\text { Bone Grafting } \\
\text { Was Done }\end{array}$ \\
\hline 6 & 36 & $\mathrm{~F}$ & $\mathrm{~L}$ & A2 & 18 & Percutaneous Volar & 9 & 90 & \\
\hline 7 & 28 & $\mathrm{~F}$ & $\mathrm{R}$ & $\mathrm{C}$ & 44 & Percutaneous Volar & 11 & 70 & \\
\hline 8 & 32 & $\mathrm{M}$ & $\mathrm{R}$ & A2 & 14 & Orif Volar & 12 & 90 & \\
\hline 9 & 33 & $\mathrm{~F}$ & $\mathrm{~L}$ & A2 & 4 & Percutaneous Volar & 7 & 90 & \\
\hline 10 & 21 & $\mathrm{~F}$ & $\mathrm{R}$ & $\mathrm{C}$ & 56 & Orif Volar & 14 & 70 & \\
\hline 11 & 21 & $\mathrm{~F}$ & $\mathrm{R}$ & $\mathrm{A} 2$ & 5 & Orif Volar & 12 & 85 & \\
\hline 12 & 29 & $\mathrm{M}$ & $\mathrm{R}$ & B2 & 8 & Percutaneous Volar & 12 & 95 & \\
\hline 13 & 42 & $\mathrm{M}$ & $\mathrm{R}$ & $\mathrm{A} 2$ & 5 & Orif Volar & 16 & 85 & Cast Failure \\
\hline 14 & 42 & $\mathrm{~F}$ & $\mathrm{~L}$ & B2 & 8 & Orif Volar & 16 & 80 & Cast Failure \\
\hline 15 & 44 & $\mathrm{~F}$ & $\mathrm{R}$ & $\mathrm{A} 2$ & 4 & Percutaneous Volar & 10 & 95 & \\
\hline 16 & 31 & $\mathrm{M}$ & $\mathrm{L}$ & A2 & 1 & Percutaneous Volar & 8 & 100 & \\
\hline 17 & 21 & $\mathrm{M}$ & $\mathrm{R}$ & B2 & 12 & Percutaneous Volar & 12 & 90 & \\
\hline 18 & 29 & M & $\mathrm{R}$ & A2 & 5 & Percutaneous Volar & 8 & 95 & \\
\hline 19 & 29 & $\mathrm{M}$ & $\mathrm{L}$ & A2 & 16 & Orif Volar & 14 & 85 & \\
\hline 20 & 41 & $\mathrm{M}$ & $\mathrm{R}$ & B2 & 5 & Percutaneous Volar & 10 & 90 & \\
\hline 21 & 23 & M & $\mathrm{L}$ & $\mathrm{A} 2$ & 8 & Percutaneous Volar & 9 & 90 & \\
\hline 22 & 32 & $\mathrm{M}$ & $\mathrm{L}$ & B2 & 7 & Orif Volar & 14 & 85 & \\
\hline 23 & 45 & $\mathrm{M}$ & $\mathrm{R}$ & $\mathrm{C}$ & 150 & Orif Volar & 14 & 80 & $\begin{array}{l}\text { Bone Grafting } \\
\text { Was Done }\end{array}$ \\
\hline 24 & 31 & M & $\mathrm{R}$ & B2 & 8 & Percutaneous Volar & 12 & 95 & \\
\hline 25 & 24 & $\mathrm{~F}$ & $\mathrm{~L}$ & $\mathrm{~A} 2$ & 5 & Percutaneous Volar & 8 & 85 & \\
\hline 26 & 34 & $\mathrm{~F}$ & $\mathrm{~L}$ & B2 & 8 & Orif Volar & 14 & 80 & \\
\hline 27 & 36 & $\mathrm{M}$ & $\mathrm{R}$ & $\mathrm{A} 2$ & 4 & Percutaneous Volar & 10 & 95 & \\
\hline 28 & 23 & $\mathrm{~F}$ & $\mathrm{~L}$ & A2 & 1 & Percutaneous Volar & 8 & 100 & \\
\hline 29 & 32 & $\mathrm{~F}$ & $\mathrm{R}$ & B2 & 12 & Orif Volar & 12 & 90 & \\
\hline 30 & 31 & $\mathrm{M}$ & $\mathrm{R}$ & $\mathrm{A} 2$ & 5 & Percutaneous Volar & 8 & 95 & \\
\hline
\end{tabular}

In present study, 13 (43.3\%) patients were operated within one week following injury whereas 2 patients were operated very late i.e. at 150 and at 162 days following injury. About 17 patients were managed with percutaneous fixation and rest 13 cases were managed using ORIF. Though, all the fractures treated either with ORIF or percutaneous fixation united successfully, delayed union was observed in 2 patients $(6.7 \%)$ at 16 weeks postoperatively. Mean time for radiological union following ORIF was $12.6 \pm 2.4$ weeks whereas that following percutaneous fixation was $9.2 \pm 2.5$ weeks.

Range of motion was assessed using goniometer. Following percutaneous fixation; wrist flexion averaged $61^{\circ}$ (range 40 to $70^{\circ}$ ) and wrist extension averaged $58^{\circ}$ (range 35 to $65^{\circ}$ ) whereas following ORIF, wrist flexion averaged $60^{\circ}$

(range 40 to $65^{\circ}$ ) and wrist extension $54^{\circ}$ (range 30 to $60^{\circ}$ ).

Modified Mayo wrist score (MMWS) was used to assess the final functional outcome. In present study, mean pain score was 22.4 (range 10 to 25) following percutaneous whereas it was 19.6 (range 10 to 25) following ORIF. Mean range of motion score according to MMWS following percutaneous was 24.3 (range 15 to 25) whereas that following ORIF was 22.3 (range 15 to 25). Mean grip strength score was 24.5 (range 15 to 25 ) after percutaneous fixation and 22.5 (range 15 to 25 ) after ORIF. Similarly mean activity score was 22.6 (range 15 to 25 ) and 19.4 (range 15 to 25) following percutaneous and ORIF respectively. The mean MMWS score was 93.8 (range 90 to 100) for percutaneous and 83.8 (range 70 to 95 ) for ORIF

Delayed union was observed in 2 cases which were managed with open reduction with fixation. None of the patients showed malunion or signs of post traumatic osteoarthritis of the scaphoid or wrist at final follow up.

\section{DISCUSSION:}

The present prospective study aimed to assess functional outcome following ORIF or percutaneous fixation amongst 30 patients presenting with scaphoid fracture.

Injuries were graded according to Herbert and Fisher Classification which classify the fracture based upon fracture site and displacement Clinical assessment at final follow up was performed using Modified Mayo Wrist Score (MMWS) which is a 100 point scoring system including 4 areas i.e. pain, range of motion, grip strength and activity comprising of 25 points each.

Mean age of the patients in present study was $32.5 \pm 7.94$ years and slight male preponderance was observed in a ratio of $1.1: 1$. Brogan et al also observed similar findings in which scaphoid fracture were commonly encountered in young, adult males. ${ }^{[2]}$ About 17 patients were managed using percutaneous fixation whereas 13 patients were managed using ORIF.

McLaughlin and Maudsley \& Chen recommended ORIF amongst patients with scaphoid fracture to allow early mobilization of wrist, ${ }^{[17,21]}$ and these findings were replicated by present study. In present study, union was observed in all the patients and the mean union time following ORIF and percutaneous fixation was $12.6 \pm 2.4$ weeks and $9.2 \pm 2.5$ weeks respectively. These findings were similar to study by Mittal et al in which mean union time following percutaneous fixation was 8.4 weeks (range 7 to 12 ) and that following ORIF was 12.1 week (range 8 to 16) ${ }^{[14]}$ The benefit of percutaneous Herbert screw fixation is that the fracture reduction and fixation can be accomplished without further injury to the scaphoid blood supply. ${ }^{[2,23]}$ Also reduced radiological healing time and less union time are the added advantage in fractures treated by percutaneous method. ${ }^{[14]}$ Naranje et al also reported $100 \%$ union rate with Percutaneous Herbert screw fixation in 32 patients similar to present study. ${ }^{[24]}$

The present study observed union in $100 \%$ cases I both the techniques, but outcome using MMWS score including pain reduction, range of motion, grip strength and activity were significantly better in patients treated with percutaneous fixation as compared to ORIF. Though MMWS score was significantly better amongst patients treated with percutaneous fixation as compared to ORIF, complications in both the procedures were almost nil except for delayed union. The present study had certain limitations, i.e. small sample size and inhomogeneous population, the findings of the results could not be generalized. 


\section{CONCLUSION-}

Since fracture treated with percutaneous fixation are associated with early union and early return to functional activity as compared to open reduction and internal fixation as replicated by MMWS score, Herbert screw for fixation with percutaneous technique for scaphoid fracture must be encouraged for displaced or undisplaced for better radiological and functional outcome.

\section{ACKNOWLEDGEMENT-}

We would like to acknowledge the study participants without whom the study would not have been successful.

\section{REFERENCES:}

1. Gaebler C, Mcqueen MM. Carpus fractures and dislocations. Bucholz RW, CourtBrown CM, Heckman JD, Tornetta P, eds. Rockwood and Green's fractures in adults. Brown CM, Heckman JD, Tometta P, eds. Rockwood and Green's fract

2. Brogan DM, Moran SL, Shin AY. Outcomes of open reduction and internal fixation of acute proximal pole scaphoid fractures. Hand. 2015 Jun;10(2):227-32.

3. Barton NJ. Twenty questions about scaphoid fractures. Journal of hand surgery. 1992 Jun;17(3):289-310

4. Gaebler C, Kukla C, Breitenseher M, Trattnig S, Mittlboeck M, Vecsei V. Magnetic resonance imaging of occult scaphoid fractures. Journal of Trauma and Acute Care Surgery. 1996 Jul 1;41(1):73-6.

5. McQueen MM, Gelbke MK, Wakefield A, Will EM, Gaebler C. Percutaneous screw fixation versus conservative treatment for fractures of the waist of the scaphoid: a fixation versus conservative treatment for fractures of the waist of the scaphoid: a
prospective randomised study. The Journal of bone and joint surgery. British volume. prospective randomise

6. Grewal R, Suh N, MacDermid JC. Use of computed tomography to predict union and time to union in acute scaphoid fractures treated nonoperatively. The Journal of hand surgery. 2013 May 1;38(5):872-7.

7. Pao VS, Chang J. Scaphoid nonunion: diagnosis and treatment. Plastic and reconstructive surgery. 2003 Nov 1;112(6):1666-77.

8. Wong K, von Schroeder HP. Delays and poor management of scaphoid fractures: factors contributing to nonunion. The Journal of hand surgery. 2011 Sep 1;36(9):1471-4.

9. Buijze GA, Doornberg JN, Ham JS, Ring D, Bhandari M, Poolman RW. Surgical compared with conservative treatment for acute nondisplaced or minimally displaced compared with conservative treatment for acute nondisplaced or minimally displaced
scaphoid fractures: a systematic review and meta-analysis of randomized controlled scaphoid fractures: a systematic review and meta-analysis of randomized controlled trials. JBJS.

10. Papaloizos MY, Fusetti C, Christen T, Nagy L, Wasserfallen JB. Minimally invasive fixation versus conservative treatment of undisplaced scaphoid fractures: a costeffectiveness study. Journal of Hand Surgery. 2004 Apr;29(2):116-9.

11. Bhat M, McCarthy M, Davis TR, Oni JA, Dawson S. MRI and plain radiography in the assessment of displaced fractures of the waist of the carpal scaphoid. The Journal of bone and joint surgery. British volume. 2004 Jul;86(5):705-13.

12. Cooney III WP, Dobyns JH, Linscheid RL. Nonunion of the scaphoid: analysis of the results from bone grafting. The Journal of hand surgery. 1980 Jul 1;5(4):343-54

13. Dias JJ, Brenkel IJ, Finlay DB. Patterns of union in fractures of the waist of the scaphoid. The Journal of bone and joint surgery. British volume. 1989 Mar; 71(2):307-10

14. Mittal V, Kapoor R, Hussain A, Singh A, Pal CP, Sharma YK. FUNCTIONAL OUTCOME OF SCAPHOID FRACTURE FOLLOWING ORIF VS. PERCUTANEOUS FIXATION

15. Ring D, Jupiter JB, Herndon JH. Acute fractures of the scaphoid. JAAOS-Journal of the American Academy of Orthopaedic Surgeons. 2000 Jul 1;8(4):225-31.

16. Segalman KA, Graham TJ. Scaphoid proximal pole fractures and nonunions. Journal of the American Society for Surgery of the Hand. 2004 Nov 1;4(4):233-49.

17. McLaughlin HL. Fracture of the carpal navicular (scaphoid) bone: some observations based on treatment by open reduction and internal fixation. JBJS. 1954 Jul 1;36(4):765819.

18. Rettig ME, Kozin SH, Cooney WP. Open reduction and internal fixation of acute displaced scaphoid waist fractures. The Journal of hand surgery. 2001 Mar 1;26(2):2716.

19. Adamany DC, Mikola EA, Fraser BJ. Percutaneous fixation of the scaphoid through a dorsal approach: an anatomic study. The Journal of hand surgery. 2008 Mar 1;33(3):32731.

20. Drac P, Manak P, Cizmar I, Hrbek J, Zapletalová J. A Palmar percutaneous volar versus a dorsal limited approach for the treatment of non-and minimally-displaced scaphoid waist fractures: an assessment of functional outcomes and complications. Acta chirurgiae orthopaedicae et traumatologiae Cechoslovaca. 2010 Apr;77(2):143-8.

21. Maudsley RH, Chen SC. Screw fixation in the management of the fractured carpal scaphoid. The Journal of bone and joint surgery. British volume. 1972 Aug;54(3):43241.

22. Aguilella L, Garcia-Elias M. The anterolateral corner of the radial metaphysis as a source of bone graft for the treatment of scaphoid nonunion. The Journal of hand surgery. 2012 Jun 1;37(6):1258-62.

23. Albertsen J, Mencke S, Christensen L, Teisen H, Hjarbäk J. Isolated capitate fracture diagnosed by computed tomography. Case report. Handchirurgie - Mikrochirurgie• Plastische Chirurgie 1999 Mar;31(02):79-81.

24. Naranje S, Kotwal PP, Shamshery P, Gupta V, Nag HL. Percutaneous fixation of selected scaphoid fractures by dorsal approach. International orthopaedics. 2010 Oct 1;34(7):997-1003 